\title{
The CAMP study: feasibility and clinical correlates of standardized assessments of substance use in a youth psychiatric inpatient sample
}

Jillian Halladay ${ }^{1,2^{*}}\left(\mathbb{D}\right.$, Laurie Horricks², Michael Amlung ${ }^{3,4}$, James MacKillop ${ }^{4,5,6}$, Catharine Munn 1,4,5,7, Zil Nasir ${ }^{1,8}$, Rachel Woock ${ }^{8}$ and Katholiki Georgiades ${ }^{1,4,9}$

\begin{abstract}
Background: To determine: (a) the feasibility and acceptability of administering a standardized electronic assessment of substance use and other mental health concerns to youth admitted to an inpatient psychiatric unit, and (b) the prevalence and clinical correlates of substance use in this sample.

Methods: The sample included 100 youth between the ages of 13 to 17 years admitted to an inpatient psychiatric unit in Ontario, Canada between September and November 2019 (78\% response rate). Youth data were comprised of electronic self-reported assessments (during hospitalization and 6-months following) and chart reviews (99\% consented; historical and prospective). Frontline staff completed a self-report survey assessing their perceptions of the need for standardized substance use assessments, training, and interventions on the unit ( $n=38$ Registered Nurses and Child and Youth Workers; $86 \%$ response rate). Analyses included descriptive statistics, correlations, regression, and qualitative content analysis.
\end{abstract}

Results: Feasibility of standardized youth self-reported mental health and substance use assessments was evident by high response rates, little missing data, and variability in responses. $79 \%$ of youth had used at least one substance in their lifetime; 69\% reported use in the last 3 months. Substance use was positively correlated with severity of psychiatric symptoms ( $\mathrm{tb} 0.17$ to 0.45 ) and number of psychiatric diagnoses ( $\mathrm{tb} 0.17$ to 0.54 ) at index. Based on prospective and retrospective data, substance use was also positively related to mental health symptom severity at follow-up and repeat mental health related hospital visits. Frontline staff reported a need for standardized assessment, training, and interventions on the unit, indicative of acceptability.

Conclusions: This study demonstrated the feasibility, acceptability and clinical importance of administering a standardized mental health and substance use assessment among youth experiencing psychiatric hospitalization.

Keywords: Adolescent, Cannabis, Alcohol drinking, Substance-related disorder, Psychiatric Hospitals

\footnotetext{
${ }^{*}$ Correspondence: halladje@mcmaster.ca

${ }^{1}$ Department of Health Research Methods, Evidence, and Impact,

McMaster University, 1280 Main Street West, ON L8S 4S4 Hamilton, Canada

Full list of author information is available at the end of the article
}

\section{Background}

Most mental illnesses emerge in childhood and adolescence, and suicide is the second leading cause of death during adolescence $[1,2]$. Although substance use disorders (SUDs) often emerge later than other mental illnesses, most individuals who use substances initiate original author(s) and the source, provide a link to the Creative Commons licence, and indicate if changes were made. The images or other third party material in this article are included in the article's Creative Commons licence, unless indicated otherwise in a credit line to the material. If material is not included in the article's Creative Commons licence and your intended use is not permitted by statutory regulation or exceeds the permitted use, you will need to obtain permission directly from the copyright holder. To view a copy of this licence, visit http://creativecommons.org/licenses/by/4.0/. The Creative Commons Public Domain Dedication waiver (http://creativeco mmons.org/publicdomain/zero/1.0/) applies to the data made available in this article, unless otherwise stated in a credit line to the data. 
use prior to age 20 [3]. Cannabis and alcohol are two of the most commonly used substances [4], and accumulating evidence suggests use of cannabis and alcohol may precede the onset or worsening of psychiatric and suicide-related outcomes [5-7]. Regardless of temporal sequencing, co-occurrence of mental health and substance use problems is common [8]. Although helpseeking among adolescents with substance use concerns is low, many engage with psychiatric services prior to substance use treatment $[9,10]$. This presents a critical opportunity for prevention and early identification in psychiatric settings.

Assessing and addressing substance use may be particularly important during psychiatric hospitalizations given the acuity of youth presentations, access to multidisciplinary teams, and treatment recommendations and community referrals often facilitated upon discharge. However, standardized instruments, designed to assess substance use and mental health concerns, are not routinely administered in youth psychiatric settings [11-14]. There is emerging but limited evidence suggesting that individuals with mental illnesses who use cannabis or alcohol may experience more severe and complex symptoms, greater functional impairment, and poorer prognosis $[7,9,15,16]$. This evidence is primarily drawn from work in outpatient settings and is not routinely collected as a means to provide robust insight.

When considering youth populations from the perspective of those presenting to health services with substance use concerns, there is data available on the co-occurrence of mental health problems. In Canada between 2017 and 2018, about 70\% of youth hospitalizations for substance use involved concurrent psychiatric concerns [17]. Similarly, a majority of adolescents attending a large outpatient substance use program in Toronto, Ontario, endorsed high levels of internalizing (72\%) and externalizing (83\%) psychopathology [18]. These findings have been replicated among youth attending substance use treatment in the US $[10,19]$. Of note, cannabis typically accounts for the largest proportion of substance use related service use among youth [17-19].

There are significant challenges navigating and securing services for youth that address both mental health and substance use in North America [9, 20]. Longstanding gaps in youth addiction services have been recognized by governments and there have been calls for increased capacity to treat SUDs and psychiatric disorders concurrently across all sectors of youth care [20]. Both Canadian and US governments have recognized the need to identify substance use problems early, especially among those with psychiatric concerns, and have indicated a need for integrated and coordinated treatments [21-23]. This is echoed in various clinical best practice guidelines (BPGs) which recommend assessing for substance use prior to diagnosing mental illnesses and treating concurrently if co-presenting [24-27]. Despite the recognition of this problem, this gap in service persists. Common healthcare provider reported barriers to addressing substance use include time constraints, lack of training, stigma, and uncertainty about how to interpret and apply results of screening assessments $[13,28,29]$. Notably, a recent systematic review of concurrent disorder recommendations within existing BPGs found a lack of specificity and consistency regarding recommendations, as well as low levels of rigor and stakeholder input when developing the guidelines [30]. Further, no specific guidelines address the management of youth substance use on inpatient psychiatric units, which were not built or funded to address both issues. As such, further research and stakeholder input are critical to inform guidelines and advocate for funding and system changes where it is most needed.

The $\underline{\text { Cannabis, }}$ Alcohol, Mental Health, and Patterns of Service Use (CAMP) study was a pilot study to determine the feasibility and acceptability of collecting and integrating substance use, mental health, and hospitalization data among youth admitted to an inpatient psychiatric unit through both primary data collection methods (i.e., self-reported youth electronic clinical assessments, stakeholder surveys) and secondary linkages to medical records by research personnel. Our results can inform subsequent: (1) clinical research studies, designed to assess the feasibility, acceptability, utility and cost-effectiveness of integrating routine substance use and mental health assessments directly within clinical practice; and (2) methods for larger scale research studies within clinical programs. The specific feasibility objectives included [31]: (1) process outcomes, i.e., ability to recruit (patient willingness); (2) resource and management outcomes, i.e., youth and staff burden and extent of missing data, refusal, and retention; (3) scientific outcomes, including prevalence and variability in substance use and preliminary insight into correlates between substance use and psychiatric severity (i.e., intensity of symptoms), complexity (i.e., comorbidity), and health service use (i.e., length of stay and readmission); and (4) staff acceptability outcomes, including staff perceptions regarding substance use assessment and intervention on the inpatient unit, including its importance, facilitators, and barriers.

\section{Methods \\ Design and setting}

The CAMP study was a feasibility observational cohort study conducted on a large Child and Youth Mental Health Inpatient Unit in a large urban city in Ontario, Canada. The unit services youth up to the age of 18 years. The purpose of admission includes emergent psychiatric 
assessments, crisis stabilization, acute treatment delivery including pharmacological and nonpharmacological approaches (e.g., daily structured individual and/or group psychotherapeutic programming), and coordinated postdischarge planning with community partners. In general, roughly $50 \%$ of beds on this unit are occupied by youth experiencing internalizing symptoms (e.g., depression, anxiety, trauma), $23 \%$ by youth with primary personality disorder related symptoms (e.g., borderline personality disorder, oppositional defiant disorder), and $27 \%$ by highly acute youth (e.g., psychotic and manic episodes). The average length of stay is $7-10$ days, appreciating the vast majority of treatment provision occurs post-crisis in the community. Developed 12 years ago, the units focus has been on the acute stabilization of psychiatric presentations. Over the past 12 years, the unit has admitted youth with concurrent disorders, and openly acknowledges it is not a designated concurrent disorders unit and therefore does not provide specific treatments for SUDs.

The study consisted of 4 parts: (1) a self-reported electronic youth assessment during hospitalization; (2) a 6-month follow-up assessment; (3) retrospective (3 years) and prospective (6 months) chart reviews; and (4) frontline staff surveys. The staff component combined cross-sectional and qualitative description designs in survey format [29]. All study objectives and procedures were iteratively refined with feedback from frontline staff, unit leadership, and the Child and Youth Mental Health Research Advisory Committee. Of note, the selected clinical indicators related to severity, complexity, and health service utilization align with provincially defined clinical indicators for child and youth mental health services [32, 33].

\section{Participants}

The target population for the youth component was all youth 12-17 years of age admitted to the unit. The sample included 100 youth recruited on a rolling basis. Youth were excluded if they were: unable to provide informed consent, unable to complete a $30-\mathrm{min}$ assessment (due to attention, cognitive, or safety concerns), or experiencing acute psychotic symptoms based on clinical staff evaluations. Substance use was not required. Recruitment occurred between September 9, 2019 and November 26, 2019. The target population for the staff component was all frontline full-time and part-time Registered Nurses (RNs) and Child and Youth Workers (CYWs) as of September 2020.

\section{Measures \\ Youth self-report measures}

The youth assessment was based on a clinical screening tool used on the adult Concurrent Disorders units in
Hamilton (St. Joseph's Healthcare Hamilton), adapted for youth. To facilitate comparisons, all measures were selected based on pre-piloted and/or psychometrically validated measures for youth used in large population surveys including the Ontario Student Drug Use and Health Survey (OSDUHS) [4] and the Ontario Child Health Study (OCHS) [34]. The assessment measured demographic characteristics, substance use with a particular focus on cannabis and alcohol use, psychiatric symptomatology, and mental health service utilization. The adapted interview tool was piloted and revised to ensure clarity and minimal burden. See Table 1 for a summary of measures (see Additional file 1 for a PDF of the assessment).

\section{Youth chart reviews}

Person-level, health service utilization data was collected on prior (past 3 years) and follow-up (6 months post-discharge) psychiatric and substance use related emergency department (ED) presentations and inpatient psychiatric admissions at the hospital. The hospital for data collection is the only pediatric hospital in the city but it is possible for youth in surrounding cities to present to EDs at other hospitals and then get transferred to this inpatient unit (i.e., direct admission). ED visits were identified in Canadian Institute for Health Information (CIHI) National Ambulatory Care Reporting System (NACRS) database using the Canadian Emergency Department Information System (CEDIS) presenting complaints alongside the most responsible diagnosis code for each ED encounter at the hospital site. Inpatient admissions and associated length of stay were identified in CIHI Discharge Abstract Database (DAD) by the most responsible discharge diagnosis code for each inpatient encounter. Substance use and mental health codes were included. Data on severity and complexity included documentation by clinicians on harm to self, harm to others, property damage, symptoms of psychosis, substance use, and discharge diagnoses (for a complete list of codes and extraction content, see Additional file 2). Substance use information came from existing semi-structured interviews documented in patient charts by either the nurse upon admission to the unit, or the psychiatrist during the psychiatric assessment. Interviews included openended questions related to substances used and patterns of use prior to the inpatient admission. However, these interviews were not standardized and did not utilize validated measures, consistent historical timelines, or systemized probes or response options. Additionally, the documentation system had sections with limited character counts. 
Table 1 Summary of key measures in the youth electronic assessment

\begin{tabular}{|c|c|}
\hline General construct & Specific variables \\
\hline Demographics & Age, gender, sex, race/ethnicity, immigrant status, subjective social status $[4,48]$ \\
\hline \multicolumn{2}{|l|}{ Substance use variables } \\
\hline Cannabis use & $\begin{array}{l}\text { - Frequency of use }[4,58] \\
\text { - Symptoms of cannabis use disorder (CUDIT-R) [59] } \\
\text { - Age of onset }[4,58] \\
\text { - Percentage of typical THC/CBD, grams per use day, cost per week/month } \\
\text { - Coping motives scores }[60] \\
\text { - Proportion of time spent using with others [61] } \\
\text { - Co-use with alcohol and co-use with tobacco [4] }\end{array}$ \\
\hline Alcohol use & $\begin{array}{l}\text { - Frequency of any use }[4,58] \\
\text { - Frequency of heavy episodic drinking (HED; } 5+\text { drinks in a sitting) [4] } \\
\text { - Symptoms of alcohol use disorder (AUDIT) [62] } \\
\text { - Coping motives scores [63] } \\
\text { - Proportion of time spent using with others [61] }\end{array}$ \\
\hline Smoking & $\begin{array}{l}\text { - Frequency of smoking cigarettes/cigars }[4,58] \\
\text { - Frequency of e-cigarette use and types of substances in e-cigarettes }[4,58]\end{array}$ \\
\hline \multirow[t]{4}{*}{ Prescription drug misuse } & Frequency of $[4,58,64]$ : \\
\hline & - Prescription stimulants \\
\hline & - Prescription opioids \\
\hline & - Prescription sedatives \\
\hline \multirow[t]{7}{*}{ Other drug use } & Frequency of $[4,58,64]$ : \\
\hline & - Cocaine \\
\hline & - Methamphetamine \\
\hline & - Solvents \\
\hline & • Hallucinogens \\
\hline & - Street opioids \\
\hline & - Steroids \\
\hline \multicolumn{2}{|c|}{ Psychiatric clinical severity and complexity } \\
\hline Severity of psychological distress & $\begin{array}{l}\text { The Kessler } 6 \text { (K6) [65] provided a dimensional measure of non-specific psychological distress. Previously } \\
\text { derived cut-offs of } \geq 13 \text { which indicate serious mental illness were used }\end{array}$ \\
\hline \multirow[t]{4}{*}{ Internalizing symptom severity } & $\begin{array}{l}\text { The OCHS Emotional Behavioral Scales (OCHS-EBS) [66] dimensional measure captured symptoms of } \\
\text { internalizing disorders including: }\end{array}$ \\
\hline & • Major depressive episode (MDE; of note, suicide item removed) \\
\hline & - Generalized anxiety disorder (GAD) \\
\hline & · Social phobia (SP) \\
\hline \multirow[t]{4}{*}{ Externalizing symptom severity } & The OCHS-EBS [66] dimensional measure captured symptoms of externalizing disorders including: \\
\hline & • Oppositional defiant disorder (ODD) \\
\hline & • Conduct disorder (CD) \\
\hline & - Attention deficit hyperactivity disorder (ADHD) \\
\hline Youth derived clinical complexity & $\begin{array}{l}\text { Clinical cut-offs for OCHS-EBS disorder scores based on prevalence estimates derived from a diagnostic } \\
\text { structured interview in the original OCHS general population sample were used to generate categorical } \\
\text { prevalence of disorders [34]. The number of cut-offs youth exceeded were summed to derive number of } \\
\text { internalizing, externalizing, and total disorders as indicators of youth reported clinical complexity. }\end{array}$ \\
\hline Symptoms of psychosis & $\begin{array}{l}\text { A pre-existing symptom scale adapted from the Diagnostic Interview Schedule [67] provided a dimen- } \\
\text { sional measure of symptoms of psychosis }\end{array}$ \\
\hline
\end{tabular}

\section{Staff self-report measures}

The staff survey was informed by previous research [13, 28, 29] alongside consultations with the CAMP study team, unit management and leadership, and senior frontline staff. The staff survey included 14 closed and openended questions related to standardized youth substance use assessment, treatment planning, training/education, and potential barriers and facilitators to addressing these on the unit (see Additional file 3 for a PDF of the survey).

\section{Recruitment and data collection \\ Youth}

The study Research Assistants (RAs) were trained on general reasons for admission, unit staffing model, 
common clinical presentations, and specific items about their role in the maintenance of environmental safety. Unit staff were informed about the study through emails and staff meetings beginning one month prior to recruitment through to completion of baseline data collection. Patients were recruited primarily through a one-on-one discussion with an RA. Alternative methods included RAs providing a brief study overview during morning group on a semi-weekly basis and study posters. The RAs consulted with nursing staff about eligible patients in advance of meeting with the patient, to ensure eligibility, safety, appropriate timing, and capacity to consent. Data was collected on an iPad using Qualtrics CoreXM, which is a secure online survey platform and database (Qualtrics, Provo, UT). The RA supervised the youth as they completed the assessments. For youth who consented, a 6-month followup assessment was sent to their phones and/or emails (with one reminder) and chart reviews were done to obtain information before, during, and after their index hospital admission. Youth were able to consent to partake in 1, 2 or all 3 parts of the study (i.e., baseline, follow-up, chart reviews), and received a $\$ 10$ gift card for each component (up to $\$ 30$ ).

\section{Frontline staff}

Staff were recruited through personalized cards in their staff mailbox, emails, posters, and reminders during morning rounds. Data was also collected using Qualtrics CoreXM. All staff received a $\$ 20$ gift card regardless of participation to keep responses anonymous.

\section{Ethics and reporting guidelines}

Ethics approval was obtained from the Hamilton Integrated Research Ethics Board (ID 7075) and study procedures were approved by the Child and Youth Mental Health Research Advisory Committee. Consent to participate was obtained directly from youth, and not parents, in order to mitigate bias in reporting substance use $[35,36]$, and to maintain parameters of confidentiality. Our focus on capacity rather than age, is consistent with the Tri-Council Policy Statement, Health Care Consent Act, and previous research demonstrating that youth 12 years of age or older are often capable of consent [37]. Methods and reporting follow pilot study guidelines [31], Strengthening the Reporting of Observational Studies in Epidemiology (STROBE) guidelines, and Reporting of Studies Conducted Using Observational Routinely-Collected Health Data (RECORD) guidelines (for reporting checklists, see Additional file 4).

\section{Statistical analyses}

\section{Youth component}

This paper examines feasibility outcomes [31], predominantly operationalized as: (1) recruitment of 100 youth within 4 months with a response rate greater than $75 \%$; (2) at least $80 \%$ of youth consenting to chart reviews and follow-up assessments; (3) over $80 \%$ of consenting youth completing their 6-month follow-up assessment; and (4) at least $20 \%$ of youth reporting monthly cannabis and/or heavy alcohol use. Thresholds for adequate response rates come from Risk of Bias tools [38]. Using representative general population data [39], we estimated the prevalence of monthly cannabis use to be 1.7 times greater and heavy drinking to be 1.5 times greater for youth experiencing high levels of psychiatric symptomatology, compared to those with no or few symptoms.

Descriptive statistics were used for feasibility outcomes and to characterize the sample including substance use prevalence estimates with 95\% Confidence Intervals (CIs) calculated for proportions [31]. Bivariate Kendall's Tau (tb) correlations using a $p<0.05$ to denote significance were used to examine associations between self-reported substance use variables and clinical severity and complexity. Logistic regressions were conducted to explore associations between substance use and any ED visit or inpatient admission, adjusted for type of index admission (e.g., whether patients were directly admitted or went through the local ED). Linear regressions were done to examine associations between self-reported substance use at index and psychiatric symptomatology at follow-up, adjusted for symptomatology at index. All analyses were done using complete cases, after pro-rating summative scales for up to 3 missing items.

\section{Staff component}

Descriptive statistics were used to provide frequencies and averages of closed-ended response options. Two researchers ( $\mathrm{JH}$ and $\mathrm{RW})$ used qualitative content analysis to code all open-ended data manually through adding index labels, which were then counted and inductively categorized based on regularities and patterns in the topic codes [40]. Final categories evolved through refinement of codes by re-reading, discussions, and consultations with the larger research team [41]. Results from the quantitative and qualitative items were deliberately integrated and merged during the analysis and interpretation phase to obtain a more complete picture of staff perspectives [42].

\section{Results}

Youth component

\section{Response rates and retention}

During the 3-month data collection period, of the 128 youth that met inclusion criteria, 111 were invited to 
128 eligible youth admitted to the unit

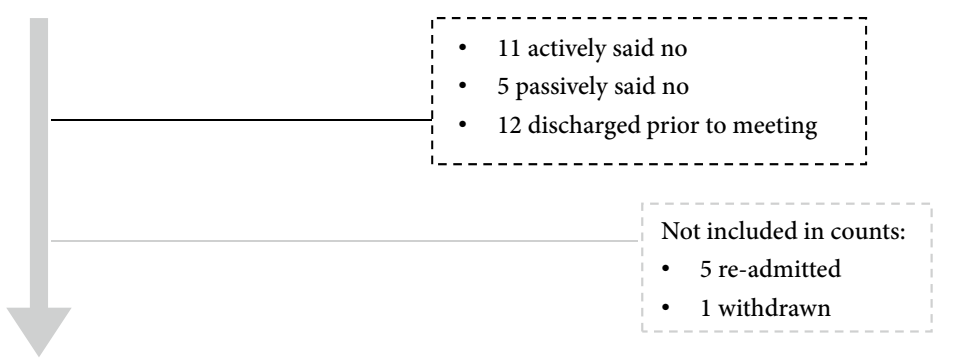

100 youth recruited and

completed baseline questionnaire

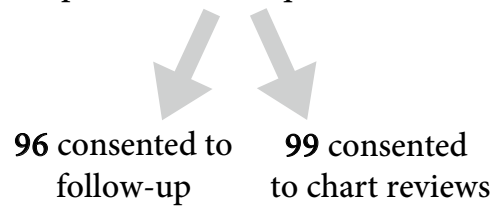

50 completed 6-month

99 charts accessed

follow-up questionnaires

Fig. 1 Youth participant flow chart

participate in the study, and 100 youth consented to be involved in the study (78\% [95\% CI 70\% to 86\%] response rate of all eligible youth, $90 \%$ response rate of those invited). For baseline assessments, 77\% of youth completed all items with the remaining missing 3 or fewer items. Almost all youth consented to follow-up assessments $(96 \%$ [CI $92 \%$ to $100 \%$ ]) and chart reviews (99\% [CI $97 \%$ to $100 \%$ ]). 50 (52\% [CI $42 \%$ to $62 \%$ ]) youth responded to the follow-up assessments within 3 weeks of their 6-month follow-up date. ${ }^{1}$ At follow-up, $78 \%$ had complete data with the remaining missing 4 or fewer items. The study surpassed all a priori feasibility criteria, with the exception of the follow-up rate $(52 \%$ vs. proposed $>80 \%$ ) which was likely influenced by the COVID19 pandemic. Of note, only higher psychological distress (Odds Ratio $[\mathrm{OR}]=0.913, \mathrm{p}=0.034)$ and prior mental health $E D$ visits $(O R=0.420, p=0.036)$ were associated with a lower odds of missing at follow-up; no other indicators of severity, complexity, service use, substance use, or demographic characteristics predicted missingness. See Fig. 1 for a participant flow chart.

\footnotetext{
${ }^{1} 1$ youth submitted 2 follow-up assessments with multiple discrepancies and another youth submitted 2 months after their follow-up time (not included in follow-up rates). Thus, the follow-up analyses were based on a sample size of $\mathrm{n}=49$.
}

\section{Recruitment and data collection strategy}

Recruitment and data collection processes were efficient and acceptable. Interactions between RAs and staff took on average $5 \mathrm{~min}$ per interaction and staff did not express concerns about time taken away from clinical care. RAs typically took $30-40$ min to discuss the study and thoroughly review the consent forms with youth. Baseline assessments took youth on average 13 min to complete, with a minimum of 5 and maximum of 33 min (variability due to skip patterns). Of youth included in follow-up assessments, 23 (47\%) completed via email and 26 (53\%) via smartphones, thus supporting the inclusion of both options.

\section{Demographics}

Youth were on average 15.4 years of age (age range, 13-17 years). Most youth were female gender (65\%). With 2 outliers removed, the average length of stay for index admissions was 8.4 days (shortest 1 day, longest 21 days). In the 3 years prior to index, $44 \%$ of the sample had an ED visit for mental health concerns and $40 \%$ had a psychiatric admission at the data collection site. In the 6 months following index, 27\% re-presented to ED and $24 \%$ were re-admitted for mental health concerns at the data collection site. See Table 2 for demographic characteristics. 


\section{Mental health symptomatology}

Using clinician-identified most responsible (one per youth) discharge diagnosis, depressive-related (29\%), anxiety and obsessive-compulsive related (22\%), and trauma and stressor related (21\%) disorders were the most common. When using diagnoses taken from discharge summary notes, in which multiple diagnoses could be identified, the most common disorders were: anxiety and obsessive-compulsive related (64\%), depressive related (43\%), borderline personality, cluster B, and emotion dysregulation related (41\%), and trauma and stressor related $(31 \%)$. Of note, $10 \%$ of youth had a discharge diagnosis of a SUD, none of which were the most responsible diagnosis. Using self-reported symptom scores, $87 \%$ surpassed cut-offs for at least one mental health disorder. Specifically, $75 \%$ and $49 \%$ surpassed thresholds for at least 1 internalizing or externalizing disorder, respectively, with $37 \%$ meeting criteria for both. See Table 2 for mental health symptomatology and diagnostic characteristics.

\section{Substance use}

$69 \%$ of youth had used at least one substance in the 3 months prior to their psychiatric admission. The most common substances used among youth in the 3 months prior to admission were alcohol, cannabis, tobacco, e-cigarettes, and opioids. Use of multiple substances was common, whereby $50 \%$ of youth were using more than one substance prior to admission. Co-use was common, with 24 youth $(60 \%)$ combining alcohol and cannabis and 25 youth $(63 \%)$ combining tobacco and cannabis. See Table 3 for prevalence of substance use at index. Self-reported substance use in assessments was higher than documented use in clinical notes-especially when compared to nursing assessments done on admission. These discrepancies could be due to differential reporting by the youth in confidential self-reported assessments versus clinical interviews, but it is more likely that discrepancies arise given differences in content coverage between assessments (i.e., specific questions, timelines, probing, response options, etc.). For example, the electronic self-reported assessment provided examples of each substance type and response options to aid with recall, which were not standardized in clinical interviews.

Cannabis The average age of initiation among all youth who reported lifetime cannabis use was 13.3 years. Of the $50 \%$ of youth who reported cannabis use in the 3 months prior to admission, 32 (64\%) had CUDIT-R scores indicative of hazardous cannabis use (mean $=12.4 ; \mathrm{SD}=7.4$ ) and 23 (46\%) had recently thought about cutting down or stopping use. Of the $45 \%$ of youth who endorsed past month use, 25 (55\%) reported using alone half of the time or more, 35 (78\%) reported using to cope most or all of the time, and 18 (40\%) reported daily use. Notably, frequency of cannabis use and using for coping purposes accounted for $60 \%$ of the variance in CUDIT-R scores. Prevalence of monthly cannabis use was 3.2 times greater than prevalence in the general population of grade 7-12 students (14.1\%) [4], surpassing a priori feasibility thresholds.

Alcohol Of the 51\% who reported using alcohol in the 3 months prior to admission, 23 (47\%) had AUDIT scores indicative of hazardous alcohol use ( mean $=8.4, \mathrm{SD}=6.3$ ). Of these youth, 12 (24\%) reported someone being injured as a result of their drinking and $7(14 \%)$ were currently concerned about their drinking. Of the $46 \%$ of youth who endorsed past month use, 11 (24\%) reported using alone half of the time or more, 30 (65\%) reported using to cope most or all of the time, and 29 (63\%) reported heavy episodic drinking (HED). Questions regarding past month drinking and HED alongside drinking coping motives explained $58 \%$ of the variance in AUDIT scores. Prevalence of monthly HED was 1.9 times greater than the general population (15\%) [4], surpassing a priori feasibility thresholds.

Cigarettes and E-cigarettes $14 \%$ endorsed daily use of tobacco cigarettes and $14 \%$ endorsed daily use of e-cigarettes. Types of e-cigarettes were clarified at follow-up, where most youth reported using e-cigarettes with nicotine $(79 \%)$ and about a third (32\%) reported use with cannabis.

Other drug and prescription drug misuse When other drugs were used in the 3 months prior to admission, most youth endorsed using the substance 1 or 2 times with no more than $3 \%$ endorsing 10 or more times for any individual substance ( $3 \%$ cocaine, $2 \%$ solvents, $2 \%$ hallucinogens). Misuse of prescription drugs 10 or more times was more common with youth endorsing frequent use of prescription stimulants (4\%), sedatives (5\%), and/or opioids (5\%).

\section{Clinical correlates of substance use}

The magnitude, significance, and precision of effects varied across different substance types (e.g., alcohol, cannabis, cigarettes, e-cigarettes, prescription, other) and substance-related variables (e.g., frequency, AUDIT/ CUDIT-R, coping motives, using alone) for different clinical indicators. However, significant correlations emerged between at least one substance use variable and: (1) self-reported externalizing (all substances; significant tb from 0.17 to 0.45 ) and internalizing symptomatology (select substances; significant tb from 0.17 to 0.40$) ;(2)$ clinician-reported aggressive behaviors 
Table 2 Demographic and clinical characteristics of youth participants

Sample characteristics

Mean (SD) or \%

Demographic characteristics

Age

Perceived social status

Female sex

Female gender

Transgender and gender diverse

White race/ethnicity

Mixed race/ethnicity

Lived in Canada whole life

One or more parents born outside of Canada

Positive screening on self-reported psychiatric symptom scales

Generalized anxiety disorder (GAD)

Social phobia (SP)

Major depressive episode (MDE)

Attention deficit hyperactivity disorder (ADHD)

Oppositional defiant disorder (ODD)

Conduct disorder (CD)

At least one internalizing disorder (GAD, SP, and/or MDE)

At least one externalizing disorder (ADHD, ODD, and/or CD)

At least one internalizing and one externalizing disorder

Any internalizing or externalizing disorder

Serious mental illness (K6)

Most responsible physician discharge diagnosis (primary diagnosis, youth only have one)

Depressive related disorders

Anxiety and obsessive-compulsive related disorders

Trauma and stressor related disorders

Borderline, cluster B, and emotion dysregulation disorders

ADHD and other neurodevelopmental disorders

Other (for complete list, see Additional file 3, available online)

Discharge summary diagnoses ${ }^{a}$

Depressive related disorders

Trauma and stressor related disorders

Borderline personality, cluster B, and emotion dysregulation disorders

ADHD and other neurodevelopmental disorders

Problems with family relations

SUDS

Other

Number of any discharge diagnoses

Number of categories of discharge diagnoses (excluding other)

Hospital contacts prior to and following index

Any ED visit in prior 3 years 
Table 3 Prevalence of youth substance use prior to index admission

\begin{tabular}{|c|c|c|}
\hline Substance & Time period or type of use & Total sample $(n=100)$ \\
\hline \multirow[t]{5}{*}{ Alcohol } & Lifetime & $73 \%$ (64 to 82$)$ \\
\hline & Past 3 months & $51 \%(41$ to 61$)$ \\
\hline & HED past month & $29 \%$ (20 to 38 ) \\
\hline & AUDIT 8-15"risky"a & $17(33 \%$ [20 to 46]) \\
\hline & AUDIT $\geq 16$ "harmful and high risk"a & $6(12 \%[3$ to 21$])$ \\
\hline \multirow[t]{5}{*}{ Cannabis } & Lifetime & $66 \%$ (57 to 75$)$ \\
\hline & Past 3 months & $50 \%$ (40 to 60$)$ \\
\hline & Daily past month & $18 \%$ (10 to 26$)$ \\
\hline & CUDIT 8-11"hazardous"a & $5(10 \%$ [2 to 18$])$ \\
\hline & CUDIT $\geq 12$ "possible CUD"a & $27(54 \%$ [40 to 68]) \\
\hline \multirow[t]{3}{*}{ Tobacco } & Lifetime & $47 \%$ (37 to 57 ) \\
\hline & Past 3 months & $33 \%$ (24 to 42$)$ \\
\hline & Daily past month & $14 \%$ (7 to 21$)$ \\
\hline \multirow[t]{3}{*}{ E-cigarettes } & Lifetime & $42 \%$ (32 to 52 ) \\
\hline & Past 3 months & $34 \%$ (25 to 43$)$ \\
\hline & Daily past month & $14 \%$ (7 to 21$)$ \\
\hline \multirow[t]{2}{*}{ Prescription opioids } & Lifetime & $22 \%$ (14 to 30$)$ \\
\hline & Past 3 months & $18 \%(10$ to 26$)$ \\
\hline \multirow[t]{2}{*}{ Sedatives } & Lifetime & $22 \%$ (14 to 30$)$ \\
\hline & Past 3 months & $14 \%(7+21)$ \\
\hline \multirow[t]{2}{*}{ Prescription stimulants } & Lifetime & $21 \%$ (13 to 29$)$ \\
\hline & Past 3 months & $11 \%(5$ to 17$)$ \\
\hline \multirow[t]{2}{*}{ Cocaine } & Lifetime & $18 \%$ (10 to 26$)$ \\
\hline & Past 3 months & $8 \%(3$ to 13$)$ \\
\hline \multirow[t]{2}{*}{ Hallucinogens } & Lifetime & $22 \%$ (14 to 30$)$ \\
\hline & Past 3 months & $14 \%$ (7 to 21$)$ \\
\hline \multirow[t]{2}{*}{ Solvents } & Lifetime & $10 \%$ (4 to 16$)$ \\
\hline & Past 3 months & $4 \%(0$ to 8$)$ \\
\hline \multirow[t]{2}{*}{ Any prescription drug } & Lifetime & $35 \%$ (26 to 44$)$ \\
\hline & Past 3 months & $24 \%$ (16 to 32$)$ \\
\hline \multirow[t]{2}{*}{ Any illicit substance use } & Lifetime & $34 \%$ (25 to 43 ) \\
\hline & Past 3 months & $17 \%$ (10 to 24$)$ \\
\hline \multirow[t]{2}{*}{ Any substance use } & Lifetime & $79 \%$ (71 to 87 ) \\
\hline & Past 3 months & $69 \%$ (60 to 78 ) \\
\hline
\end{tabular}

Methamphetamines, street opioids, steroids, and synthetic cannabinoids were not included uniquely as prevalence was $<4 \%$

${ }^{a}$ For those who endorsed use in the 3 months prior to index visit

(most substances; significant tb from 0.21 to 0.32 ); (3) number of youth-reported psychiatric disorders (all substances; significant tb from 0.19 to 0.43 ); (4) number of physician-reported discharge diagnoses (select substances; significant tb from 0.17 to 0.54 ); (5) mental health related ED visits 3 years prior and 6 months after index (select substances); and (6) psychiatric admissions in the 3 years prior to index (all substances). Additionally, those who completed the 6-month follow-up who used cannabis, alcohol, cigarettes, or e-cigarettes prior to index endorsed significantly higher psychiatric symptoms at follow-up. This serves as preliminary exploratory evidence of correlations between substance use and clinical severity, complexity, service use, and poorer prognosis. See Table 4 for select correlations between substance use and severity and complexity variables. More comprehensive details and results are presented in Additional file 5 .

\section{Staff component}

There was an $86 \%$ response rate $(37 / 43)$ with roughly half RNs (49\%) and half CYWs (51\%). Over half (54\%) of the staff participating in the survey had been working on the unit 5 years or longer with only 2 staff reporting less than 
Table 4 Selected Kendall's tau correlations between substance variables and clinical severity and complexity outcomes

\begin{tabular}{|c|c|c|c|c|c|c|c|c|c|}
\hline & \multicolumn{7}{|c|}{ Youth-reported psychiatric symptomatology as per OCHS-EBS } & \multicolumn{2}{|c|}{ Physician-reported } \\
\hline & SP & GAD & MDE & ADHD & ODD & $C D$ & $\begin{array}{l}\text { Total \# surpassing } \\
\text { clinical thresholds }\end{array}$ & $\begin{array}{l}\text { Aggressive } \\
\text { threats and } \\
\text { behaviors }\end{array}$ & $\begin{array}{l}\text { Total \# of discharge } \\
\text { diagnoses based on } \\
\text { categories }\end{array}$ \\
\hline \multicolumn{10}{|l|}{ Frequency } \\
\hline Cannabis & -0.076 & 0.007 & 0.075 & 0.128 & $0.266^{b}$ & $0.309^{b}$ & $0.212^{b}$ & $0.227^{\mathrm{a}}$ & 0.117 \\
\hline Alcohol & 0.054 & 0.038 & 0.105 & 0.073 & $0.210^{b}$ & $0.250^{b}$ & $0.200^{\mathrm{a}}$ & $0.212^{\mathrm{a}}$ & 0.093 \\
\hline Cigarette & 0.005 & 0.069 & 0.071 & $0.185^{\mathrm{a}}$ & $0.295^{b}$ & $0.447^{b}$ & $0.280^{\mathrm{b}}$ & $0.324^{b}$ & 0.167 \\
\hline E-cigarette & -0.021 & 0.05 & 0.107 & 0.14 & $0.259^{b}$ & $0.300^{b}$ & $0.284^{b}$ & 0.136 & 0.141 \\
\hline Prescription & $0.208^{\mathrm{a}}$ & $0.245^{b}$ & $0.279^{b}$ & $0.168^{\mathrm{a}}$ & $0.230^{b}$ & $0.319^{b}$ & $0.360^{\mathrm{b}}$ & $0.262^{b}$ & $0.197^{\mathrm{a}}$ \\
\hline Other & 0.081 & 0.137 & $0.174^{\mathrm{a}}$ & $0.206^{\mathrm{a}}$ & $0.274^{b}$ & $0.374^{b}$ & $0.341^{b}$ & $0.282^{b}$ & $0.200^{\mathrm{a}}$ \\
\hline \multicolumn{10}{|l|}{ Coping motives } \\
\hline $\begin{array}{l}\text { Cannabis coping } \\
\text { motives }\end{array}$ & $0.293^{b}$ & $0.398^{b}$ & 0.206 & 0.001 & 0.052 & 0.04 & $0.229^{\mathrm{a}}$ & -0.068 & $0.358^{\mathrm{a}}$ \\
\hline Alcohol coping motives & 0.128 & $0.302^{b}$ & $0.236^{\mathrm{a}}$ & $0.320^{b}$ & $0.299^{b}$ & $0.316^{b}$ & $0.412^{b}$ & 0.159 & $0.540^{\mathrm{b}}$ \\
\hline \multicolumn{10}{|c|}{ Substance use disorder scores } \\
\hline CUDIT total score & -0.094 & 0.015 & 0.072 & -0.041 & 0.002 & -0.005 & 0.005 & 0.039 & 0.116 \\
\hline AUDIT total score & 0.02 & 0.123 & 0.186 & $0.289^{b}$ & $0.336^{b}$ & $0.444^{b}$ & $0.396^{b}$ & $0.281^{\mathrm{a}}$ & $0.442^{b}$ \\
\hline \multicolumn{10}{|c|}{ Using substances with others } \\
\hline $\begin{array}{l}\text { Using cannabis with } \\
\text { others }\end{array}$ & -0.172 & -0.14 & -0.112 & 0.049 & 0.054 & 0.108 & -0.043 & -0.085 & 0.049 \\
\hline $\begin{array}{l}\text { Using alcohol with } \\
\text { others }\end{array}$ & -0.103 & -0.167 & -0.067 & -0.111 & -0.143 & -0.117 & -0.187 & -0.113 & -0.205 \\
\hline
\end{tabular}

More detailed results in Additional file 5, available online

${ }^{\text {a }}$ Correlation is significant at the 0.05 level ( 2 tailed)

${ }^{\mathrm{b}}$ Correlation is significant at the 0.01 level (2-tailed)

1 year experience. The main findings were that: (1) staff believe substance use is important and common among youth on the unit and want to improve how they assess and address substance use; (2) staff have ideas about how to facilitate improvements in quality of care including greater standardization of assessments and interventions, separate cohorting and staffing for youth with more severe co-occurring problems, more direct substance related interventions, and more indirect facilitation of appropriate and supportive conversations; and (3) staff want more education and training to increase knowledge, confidence, and standardization of practices. Of note, lack of training $(81 \%)$ and time pressures $(64 \%)$ were the most commonly reported barriers to comprehensive assessment while facilitators included standardization, adding designated spaces in documentation, and training on conducting assessments and addressing positive screens.

\section{Discussion}

The CAMP study examined the feasibility of administering a standardized electronic assessment to measure mental health and substance use on an inpatient youth psychiatric unit and provides insight into the prevalence and correlates of substance use among youth in this acute setting. Collecting this data as part of a research study proved feasible, with high recruitment and response rates, and little participant and staff burden. The high prevalence of substance use provides evidence of the feasibility of general consecutive sampling and reinforces the importance of routine substance use assessments within this context.

Overall, comorbid substance use was the norm, not the exception. A majority of youth had used at least one substance prior to their admission, and substance use correlated with more severe psychiatric symptoms, greater complexity, and more mental health related hospital visits. Youth using substances were often using in ways that have been associated with higher risk of experiencing substance-related problems, including early age of initiation, frequent use, using multiple substances, using alone or for coping purposes, and co-using substances. Despite the unit not being designated as a concurrent disorders unit, youth with substance concerns are admitted. As such, frontline staff recommended adopting a comprehensive approach to substance use among youth admitted to hospital for psychiatric concerns, including adoption of standardized assessments, more training, 
and enhanced patient conceptualization and intervention which include substance use considerations. Standardized screening and assessments can facilitate efficient identification of patients requiring more thorough SUD clinical assessments or immediate withdrawal management and can support comprehensive patient conceptualization, integrated treatment planning, and referral pathways.

Prevalence and frequency of substance use far surpassed that found in the general population of Ontario youth in grades 7-12. Not only were youth in this study more likely to use substances, but these youth also reported more frequent use, more co-use of substances, and more symptoms related to Alcohol Use Disorder and Cannabis Use Disorder compared to the general population. In particular, almost 1 in 5 youth in the present study reported using cannabis daily and 1 in 7 smoked tobacco products daily, frequencies which are roughly 8 to 9 times greater than general population estimates [4]. Further, this sample reported an age of initiation of cannabis about 2 years younger than the general population (13.3 CAMP vs. 15.4 OSDUHS) and similar to the age of initiation among youth who present to an outpatient concurrent disorders program in Toronto (13.6) [18]. Earlier age of cannabis initiation has been related to a greater likelihood of using multiple substances and developing a SUD [43, 44], experiencing cognitive impairment, lower academic achievement, and dropping out of school [43, $45,46]$, having more criminal and legal involvement, and experiencing more concurrent mental health symptomatology [47]. Although there are differences in sampling strategies and characteristics, this provides general evidence of higher prevalence and risky use in clinical samples consistent with existing studies of youth with high levels of psychiatric symptomatology and suicidality $[5-8,48,49]$.

Most clinical guidelines indicate the need to assess the role of substances prior to diagnosing and determining treatment for mental illnesses [24-27]. This study demonstrates it is feasible to collect self-reported substance use data electronically from youth experiencing acute psychiatric concerns. Electronic assessments have shown validity, acceptability, and greater efficiency as compared to clinical interviews [50]. Further, the high frequency of substance use seen in this sample demonstrate that a non-negligible proportion of youth admitted to the hospital for psychiatric concerns may be at risk of withdrawal during admission [51]. The most common withdrawal symptoms for cannabis and nicotine are behavioral and emotional, which may bias diagnostic assessments and interfere with care while on an inpatient unit if substance use is not assessed systematically and comprehensively [51]. Thus, screening and assessment should not be reserved only for research studies but rather must be integrated into routine clinical care and treatment planning.

Given neurodevelopmental vulnerability, any and all substance use among adolescents merits clinical intervention, especially among those with comorbid psychiatric concerns [26]. Early intervention has the potential to reduce the severity and persistence of substance use related problems [52]. The inpatient unit also provides a unique opportunity where motivation to change behavior may be higher and access to substances is limited, likely resulting in at least temporary cessation of use. Further, given there is evidence that youth present to mental health services before substance use services $[9,10]$, psychiatric hospitalizations may present a key opportunity for early intervention and/or referral to treatment. There is a critical need for further research of substance use on youth in psychiatric inpatient settings to inform the development of best practice guidelines and standardized clinical practices.

The existing study was a pilot study of 100 youth and 38 RNs and CYWs at a single institution. Generalizability of findings pertaining to youth is limited due to the small sample size, predominately female sex and White race, and data collection and visit history only obtained at one hospital site. While youth 12 years of age were eligible to participate, no 12 year olds were recruited into the study. This is likely due to the older age distribution of youth admitted to the inpatient units in Canada, where 15-17 year olds account for the highest rates of psychiatric hospitalizations (72\%) [17]. Additionally, no youth with a diagnosis of psychosis or bipolar disorder were included in the final sample. In Canada and the US, depression is typically the most common reason for psychiatric hospitalization among adolescents [33, 5356], which was also found in our sample. In 2019 across Canada, psychotic disorders represented a small proportion of psychiatric admissions for adolescents $(<5 \%)$ [17]. Thus, we believe our sample is representative of the majority of adolescent psychiatric hospitalizations in Canada but does not generalize to a small proportion of youth unable to safely and cognitively consent or provide accurate histories, potentially due to young age $(\leq 12)$ and altered mental status such as acute symptoms of mania and/or symptoms of psychosis (based on our study inclusion criteria). Future studies should consider developing and evaluating alternative assessments methods for patients who do not meet these criteria. Further, although we had high frontline staff response rates, generalizability of the staff results is also limited due to the small sample size at a single institution, in addition to only including regular full-time and part-time RNs and CYWs (to preserve anonymity). Future work should 
include staff feedback from the broader multidisciplinary and leadership team. Overall, recruitment rates were high among those meeting eligibility criteria, increasing confidence in the local representativeness of the sample.

Regarding measurement, gold standard urine drug screens, timeline follow-back, and clinical diagnostic interviews were not used to assess substance use and mental health concerns, but psychometrically validated measures were used alongside chart reviews providing multiple sources for information. Social desirability bias is of particular concern for self-reported data and may have resulted in underestimations of substance use [57]. Although we were unable to completely eliminate risk of social desirability bias, strategies to mitigate bias were used including exclusively requiring youth consent to participate (and not parent) [35, 36], using self-reported as opposed to interview-administered measures, and incorporating reminders about privacy and confidentiality during the consent process and embedded reminders throughout the assessment [12]. Of note, the willingness to complete may have been influenced by confidentiality and the provision of a $\$ 10$ incentive, which is not viable in routine clinical practice. However, information collected directly by clinical staff can support direct use of this data to inform treatment planning, referrals, and shared decision making with patients that may increase patient engagement without the need for an incentive. Additionally, clinical correlations should be interpreted as preliminary evidence and require further examination in larger samples with multivariable adjustments for potential confounders.

\section{Conclusions}

In conclusion, the present study found that a majority of youth presenting to an inpatient psychiatric unit were engaging in recent substance use, often involving multiple substances, and provides preliminary evidence which supports the use of standardized substance use and mental health assessments during youth psychiatric hospitalizations. Subsequent studies should examine the feasibility and associated costs of having clinicians conduct standardized assessments, versus research assistants. Frontline staff in this study saw the need for standardized comprehensive assessments to improve clinical conceptualization and quality of care. By embedding standardized assessments directly into clinical practice, data becomes useful for: (1) direct patient care, by informing patient conceptualization, treatment pathways, and discharge planning; (2) program evaluation, by characterizing patients and providing insight into quality improvement strategies; and (3) enabling comprehensive and sustainable integration of research. Future work should include co-development and refinement of standardized assessments and related clinical uses with youth, staff, and their families. Combining research and clinical practice will facilitate bridging current policy and clinical gaps while efficiently addressing and mitigating critical research gaps.

\begin{abstract}
Abbreviations
ADHD: Attention Deficit Hyperactivity Disorder; AUDIT: Alcohol Use Disorder Identification Test; BPG: Best Practice Guideline; CAMP: Cannabis, Alcohol, Mental health, and Patterns of service use; CD: Conduct Disorder; CEDIS: Canadian Emergency Department Information System; CIHI: Canadian Institute for Health Information; CYW: Child and Youth Worker; CUDIT-R: Cannabis Use Disorder Identification Test-Revised; DAD: Discharge Abstract Database; ED: Emergency Department; GAD: Generalized Anxiety Disorder; HED: Heavy Episodic Drinking; K6: Kessler-6; MDE: Major Depressive Episode; NACRS: National Ambulatory Care Reporting System; OCHS: Ontario Child Health Study; OCHS-EBS: Ontario Child Health Study-Emotional Behavioural Scales; ODD: Oppositional Defiant Disorder; OSDUHS: Ontario Student Drug Use and Health Survey; RA: Research Assistant; RECORD: REporting of studies Conducted using Observational Routinely-collected health Data; RN: Registered Nurse; SP: Social Phobia; STROBE: Strengthening the Reporting of Observational Studies in Epidemiology; SUD: Substance Use Disorder.
\end{abstract}

\section{Supplementary Information}

The online version contains supplementary material available at https://doi. org/10.1186/s13034-021-00403-4.

Additional file 1. Youth baseline survey.

Additional file 2. Chart reviews.

Additional file 3. Staff survey.

Additional file 4. Reporting guidelines.

Additional file 5. Detailed methods and results.

\section{Acknowledgements}

Clinical staff and management on the Child and Youth Mental Health Inpatient Unit were involved in all stages of the study, including conceptualization, implementation, and interpretation. We cannot thank unit staff enough, particularly frontline Nurses and Child and Youth Workers, for their support of this study. In particular, thank you to Tammy Shaubel (a Child and Youth Worker) who came up with the study acronym "CAMP." A special thank you to the study Research Assistants: Jessica Hrymak (BA), Rachel Woock (BA), and Zil Nasir (BSC).

\section{Authors' contributions \\ $\mathrm{JH}$ conceived of and designed the study. JH led the data collection, data analysis, and writing of the paper. RW assisted with youth and staff primary data collection and analysis. ZN assisted with chart reviews and descriptive analysis. LH, CM, JM, MA, and KG provided methodological and substantive support throughout the study design and manuscript process. All authors read and approved the final manuscript.}

\section{Funding}

This study was funded by a Hamilton Health Sciences New Investigator Fund. The funders had no role in the design and conduct of the study; the collection, management, analysis, or interpretation of the data; preparation, review or approval of the manuscript; and decision to submit the manuscript for publication. JM is supported by the Peter Boris Chair in Addictions Research. KG holds the David R. (Dan) Offord Chair in Child Studies.

\section{Availability of data and materials}

The data used for this study are not publicly available due to its sensitive clinical nature. Data are available from the corresponding author upon reasonable request and will be subject to further ethics approval. 


\section{Declarations}

\section{Ethics approval and consent to participate}

Ethics approval was obtained from the Hamilton Integrated Research Ethics Board (ID 7075) and study procedures were approved by the Child and Youth Mental Health Research Advisory Committee. Informed consent was obtained directly from youth, and not parents, in order to mitigate bias in reporting substance use [31, 32], and to maintain parameters of confidentiality. Our focus on capacity rather than age, is consistent with the Tri-Council Policy Statement, Health Care Consent Act, and previous research demonstrating that youth 12 years of age or older are often capable of consent [33]. All methods were carried out in accordance with relevant guidelines and regulations.

\section{Consent for publication}

Not applicable.

\section{Competing interests}

$J M$ is a principal and senior scientist in BEAM Diagnostics, Inc; no BEAM products or services were used in the current work. JH, LH, MA, CM, ZN, RW, and KG have no competing interests to declare.

\section{Author details}

'Department of Health Research Methods, Evidence, and Impact, McMaster University, 1280 Main Street West, ON L8S 4 S4 Hamilton, Canada. ${ }^{2}$ Child and Youth Mental Health Program, McMaster Children's Hospital, 1200 Main St W, ON L8N $3 Z 5$ Hamilton, Canada. ${ }^{3}$ Department of Applied Behavioral Science, Cofrin Logan Center for Addiction Research and Treatment, Addictions Lab at The University of Kansas, 1000 Sunnyside Avenue, KS 66045 Lawrence, United States. ${ }^{4}$ Department of Psychiatry and Behavioural Neurosciences, McMaster University, Hamilton, Canada. ${ }^{5}$ Peter Boris Centre for Addictions Research, McMaster University/St. Joseph's Healthcare Hamilton, 100 West 5th St, ON L8N 3K7 Hamilton, Canada. ${ }^{6}$ Michael G. DeGroote Centre for Medicinal Cannabis Research, McMaster University, Hamilton, Canada. ${ }^{7}$ Resident Affairs, Postgraduate Medical Education (PGME), McMaster University, 1280 Main Street West, ON L8S 4 S4 Hamilton, Canada. ${ }^{8}$ Hamilton Health Sciences, 1200 Main St W, ON L8N $3 Z 5$ Hamilton, Canada. ${ }^{9}$ Offord Centre for Child Studies, McMaster University, McMaster Innovation Park, Suite 201A, 1280 Main Street West, ON L8S 4K1 Hamilton, Canada.

Received: 21 May 2021 Accepted: 3 September 2021

Published online: 13 September 2021

\section{References}

1. Kessler RC, Amminger GP, Aguilar-Gaxiola S, Alonso J, Lee S, Ustun TB. Age of onset of mental disorders: a review of recent literature. Curr Opin Psychiatry. 2007;20(4):359. https://doi.org/10.1097/YCO.0b013e32816ebc8c.

2. Statistics Canada. Table 13-10-0394-01 leading causes of death, total population, by age group. 2020

3. Blanco C, Flórez-Salamanca L, Secades-Villa R, Wang S, Hasin DS. Predictors of initiation of nicotine, alcohol, cannabis, and cocaine use: results of the National Epidemiologic Survey on Alcohol and Related Conditions (NESARC). Am J Addict. 2018;27(6):477-84. https://doi.org/10.1111/ajad. 12764.

4. Boak A, Elton-Marshall T, Mann RE, Hamilton HA. Drug use among Ontario students, 1977-2019: detailed findings from the Ontario Student Drug Use and Health Survey (OSDUHS). Toronto: Centre for Addiction and Mental Health; 2020.

5. Leadbeater BJ, Ames ME, Linden-Carmichael AN. Age-varying effects of cannabis use frequency and disorder on symptoms of psychosis, depression, and anxiety in adolescents and adults. Addiction. 2018. https://doi. org/10.1111/add.14459.

6. Aseltine RH, Schilling EA, James A, Glanovsky JL, Jacobs D. Age variability in the association between heavy episodic drinking and adolescent suicide attempts: findings from a large-scale, school-based screening program. J Am Acad Child Adolesc Psychiatry. 2009;48(3):262-70. https:// doi.org/10.1097/CHI.0b013e318195bce8.

7. Gobbi G, Atkin T, Zytynski T, Wang S, Askari S, Boruff J, et al. Association of cannabis use in adolescence and risk of depression, anxiety, and suicidality in young adulthood: a systematic review and meta-analysis. JAMA Psychiatry. 2019;76(4):426-34. https://doi.org/10.1001/jamapsychi atry.2018.4500.

8. Rush B, Urbanoski K, Bassani D, Castel S, Wild TC, Strike C, et al. Prevalence of co-occurring substance use and other mental disorders in the Canadian population. Can J Psychiatry. 2008;53(12):800-9. https://doi.org/10. 1177/070674370805301206.

9. Hawkins EH. A tale of two systems: co-occurring mental health and substance abuse disorders treatment for adolescents. Annu Rev Psychol. 2009;60:197-227. https://doi.org/10.1146/annurev.psych.60.110707. 163456.

10. Turner WC, Muck RD, Muck RJ, Stephens RL, Sukumar B. Co-occurring disorders in the adolescent mental health and substance abuse treatment systems. J Psychoact Drugs. 2004;36(4):455-62. https://doi.org/10.1080/ 02791072.2004.10524428.

11. Boyle MH, Duncan L, Georgiades K, Comeau J, Reid GJ, O'Briain W, et al. Tracking children's mental health in the 21st century: lessons from the 2014 OCHS. Can J Psychiatry. 2019;64(4):232-6. https://doi.org/10.1177/ 0706743719830025

12. Simon KM, Harris SK, Shrier LA, Bukstein OG. Measurement-based care in the treatment of adolescents with substance use disorders. Child Adolesc Psychiatr Clin N Am. 2020;29(4):675-90. https://doi.org/10.1016/j.chc. 2020.06.006

13. Harris B, Shaw B, Lawson H, Sherman B. Barriers to addressing adolescent substance use: perceptions of New York school-based health center providers. J Sch Health. 2016;86(2):96-104. https://doi.org/10.1111/josh. 12358.

14. Duncan L, Boyle MH, Abelson J, Waddell C. Measuring children's mental health in Ontario: policy issues and prospects for change. J Can Acad Child Adolesc Psychiatry. 2018;27(2):88.

15. Mammen G, Rueda S, Roerecke M, Bonato S, Lev-Ran S, Rehm J. Association of cannabis with long-term clinical symptoms in anxiety and mood disorders: a systematic review of prospective studies. J Clin Psychiatry. 2018. https://doi.org/10.4088/JCP.17r11839.

16. Botsford SL, Yang S, George TP. Cannabis and cannabinoids in mood and anxiety disorders: impact on illness onset and course, and assessment of therapeutic potential. Am J Addict. 2020;29(1):9-26. https://doi.org/10. 1111/ajad.12963.

17. Canadian Institute for Health Information. Hospital stays for harm caused by substance use among youth age 10 to 24. Ottawa: $\mathrm{ClHI} ; 2019$.

18. Hawke LD, Koyama E, Henderson J. Cannabis use, other substance use, and co-occurring mental health concerns among youth presenting for substance use treatment services: sex and age differences. J Subst Abuse Treat. 2018:91:12-9. https://doi.org/10.1016/j.jsat.2018.05.001.

19. Chan Y-F, Dennis ML, Funk RR. Prevalence and comorbidity of major internalizing and externalizing problems among adolescents and adults presenting to substance abuse treatment. J Subst Abuse Treat. 2008;34(1):14-24. https://doi.org/10.1016/j.jsat.2006.12.031.

20. Ontario's Mental Health \& Addictions Leadership Advisory Council. Mental health and addictions: realizing the vision — better mental health means better health. 2017. https://www.health.gov.on.ca/en/common/ ministry/publications/reports/bmhmbh_2017/vision_2017.pdf. Accessed 24 Apr 2021.

21. Ontario Ministry of Health and Long-Term Care. Open minds, healthy minds: Ontario's comprehensive mental health and addictions strategy. 2011. https://www.health.gov.on.ca/en/common/ministry/publications/ reports/mental_health2011/mentalhealth_rep2011.pdf. Accessed 24 Apr 2021.

22. Mental Health Comission of Canada (MHCC). Changing directions, changing lives: the mental health strategy for Canada. 2019. https://www. mentalhealthcommission.ca/sites/default/files/MHStrategy_Strategy_ ENG.pdf. Accessed 24 Apr 2021.

23. Substance Abuse and Mental Health Services Administration (SAMHSA). Strategic plan FY2019-FY2023. 2019. https://www.samhsa.gov/sites/ default/files/samhsa_strategic_plan_fy19-fy23_final-508.pdf. Accessed 24 Apr 2021.

24. Pan L, Brent DA. BMJ best practice: depression in children. 2018. https:// bestpractice.bmj.com/topics/en-gb/785. Accessed 24 Apr 2021.

25. Swinson RP. BMJ best practice guideline: generalized anxiety disorder. 2017. https://bestpractice.bmj.com/topics/en-us/120/pdf/120.pdf. Accessed 17 Mar 2021. 
26. National Institute on Drug Abuse. Principles of adolescents substance use disorder treatment a research-based guide. 2014. https://www.druga buse.gov/publications/principles-adolescent-substance-use-disordertreatment-research-based-guide/principles-adolescent-substance-usedisorder-treatment. Accessed 24 Apr 2021.

27. Burkstein O. Substance use disorder in adolescents: epidemiology, pathogenesis, clinical manifestations and consequences, course, assessment, and diagnosis. UpToDate; 2020. https://www.uptodate.com/contents/ substance-use-disorder-in-adolescents-epidemiology-pathogenesis-clini cal-manifestations-and-consequences-course-assessment-and-diagn osis?search=adoelscent\%20subsatnce\%20use\&source=search_resul t\&selectedTitle=1 150\&usage_type=default\&display_rank=1\#H2595 582733. Accessed 24 Apr 2021.

28. Sterling S, Kline-Simon AH, Wibbelsman C, Wong A, Weisner C. Screening for adolescent alcohol and drug use in pediatric health-care settings: predictors and implications for practice and policy. Addict Sci Clin Pract. 2012;7(1):13. https://doi.org/10.1186/1940-0640-7-13.

29. McNeely J, Kumar PC, Rieckmann T, Sedlander E, Farkas S, Chollak C, et al. Barriers and facilitators affecting the implementation of substance use screening in primary care clinics: a qualitative study of patients, providers, and staff. Addict Sci Clin Pract. 2018;13(1):8. https://doi.org/10.1186/ s13722-018-0110-8.

30. Alsuhaibani R, Smith DC, Lowrie R, Aljhani S, Paudyal V. How well do international clinical guidelines on mental health and substance misuse address their coexistence? A systematic review of scope, quality and inclusivity. BMC Psychiatry. 2021;21(1):209. https://doi.org/10.21203/rs.3. rs-226664/v1.

31. Thabane L, Ma J, Chu R, Cheng J, Ismaila A, Rios LP, et al. A tutorial on pilot studies: the what, why and how. BMC Med Res Methodol. 2010;10(1):1. https://doi.org/10.1186/1471-2288-10-1.

32. Ministry of Children and Youth Services. Child and youth mental health: business intelligence solution data dictionary 2020. Ontario Ministry of Health; 2020. https://www.cymh.ca/en/projects/resources/cymh_bi_ solution_data_dictionary.pdfA. Accessed 2 Aug 2021.

33. Mental Health and Addictions Scorecard and Evaluation Framework (MHASEF) Research Team. The mental health of children and youth in Ontario: 2017 scorecard. Chart pack. Toronto: Institute for Clinical Evaluative Sciences; 2017. ISBN: 978-1-92-685074-0.

34. Georgiades K, Duncan L, Wang L, Comeau J, Boyle MH, Team OCHS. Sixmonth prevalence of mental disorders and service contacts among children and youth in Ontario: evidence from the 2014 Ontario Child Health Study. Can J Psychiatry. 2019;64(4):246-55. https://doi.org/10.1177/07067 43719830024

35. White VM, Hill DJ, Effendi Y. How does active parental consent influence the findings of drug-use surveys in schools? Eval Rev. 2004;28(3):246-60 https://doi.org/10.1177/0193841X03259549.

36. Rojas NL, Sherrit L, Harris S, Knight JR. The role of parental consent in adolescent substance use research. J Adolesc Health. 2008;42(2):192-7. https://doi.org/10.1016/j.jadohealth.2007.07.011.

37. Hein IM, De Vries MC, Troost PW, Meynen G, Van Goudoever JB, Lindauer RJL. Informed consent instead of assent is appropriate in children from the age of twelve: policy implications of new findings on children's competence to consent to clinical research. BMC Med Ethics. 2015;16(1):76. https://doi.org/10.1186/s12910-015-0067-z.

38. Evidence Partners. Methodological resources. 2021. https://www.evide ncepartners.com/resources. Accessed 24 Apr 2021.

39. Offord Centre for Child Studies. 2014 school mental health surveys (SMHS). 2014. https://ontariochildhealthstudy.ca/smhs/about/aboutsmhs/. Accessed 24 Apr 2021.

40. Luciani M, Orr E, Campbell K, Nguyen L, Ausili D, Jack SM. How to design a qualitative health research study Part 2: data generation and analysis considerations. Prof Inferm. 2019;72(3):221-31.

41. Bradshaw C, Atkinson S, Doody O. Employing a qualitative description approach in health care research. Glob Qual Nurs Res. 2017;4:1-8. https:// doi.org/10.1177/2333393617742282.

42. Creswell JW, Klassen AC, Plano Clark VL, KSmith KC. Best practices for mixed methods research in the health sciences. Bethesda (Maryland): National Institutes of Health. 2011;2013:541-5.

43. Behrendt S, Wittchen HU, Höfler M, Lieb R, Beesdo K. Transitions from first substance use to substance use disorders in adolescence: is early onset associated with a rapid escalation? Drug Alcohol Depen. 2009;99(1):6878. https://doi.org/10.1016/j.drugalcdep.2008.06.014.

44. Rioux C, Castellanos-Ryan N, Parent S, Vitaro F, Tremblay RE, Séguin JR. Age of cannabis use onset and adult drug abuse symptoms: a prospective study of common risk factors and indirect effects. Can J Psychiatry. 2018;63(7):457-64. https://doi.org/10.1177/0706743718760289.

45. Arria AM, Garnier-Dykstra LM, Caldeira KM, Vincent KB, Winick ER, O'Grady KE. Drug use patterns and continuous enrollment in college: results from a longitudinal study. J Stud Alcohol Drugs. 2013;74(1):71-83. https://doi. org/10.15288/jsad.2013.74.71.

46. Meda SA, Gueorguieva RV, Pittman B, Rosen RR, Aslanzadeh F, Tennen H, et al. Longitudinal influence of alcohol and marijuana use on academic performance in college students. PLoS ONE. 2017;12(3): e0172213. https://doi.org/10.1371/journal.pone.0172213.

47. Hawke LD, Wilkins L, Henderson J. Early cannabis initiation: substance use and mental health profiles of service-seeking youth. J Adolesc. 2020;83:112-21. https://doi.org/10.1016/j.adolescence.2020.06.004.

48. Weaver MF, Dupre MA, Cropsey KL, Koch JR, Sood BA, Wiley JL, et al. Addiction epidemiology in adolescents receiving inpatient psychiatric treatment. Addict Behav. 2007;32(12):3107-13. https://doi.org/10.1016/j. addbeh.2007.06.008.

49. Wang P-W, Yen C-F. Adolescent substance use behavior and suicidal behavior for boys and girls: a cross-sectional study by latent analysis approach. BMC Psychiatry. 2017;17(1):1-7. https://doi.org/10.1186/ s12888-017-1546-1.

50. Anderson KK, John-Baptiste A, MacDougall AG, Li L, Kurdyak P, Osuch $E A$. Access and health system impact of an early intervention treatment program for emerging adults with mood and anxiety disorders. Can J Psychiatry. 2019;64(7):492-500. https://doi.org/10.1177/0706743718809347.

51. American Psychiatric Association. Diagnostic and statistical manual of mental disorders (DSM-5). 5th ed. Washington, DC: American Psychiatric Pub; 2013.

52. De Girolamo G, Dagani J, Purcell R, Cocchi A, McGorry P. Age of onset of mental disorders and use of mental health services: needs, opportunities and obstacles. Epidemiol Psychiatr Sci. 2012;21(1):47. https://doi.org/10. 1017/S2045796011000746.

53. Canadian Institute for Health Information. Care for children and youth with mental disorders_data tables. Ottawa: CIHI; 2020.

54. Rosic T, Duncan L, Wang L, Eltorki M, Boyle M, Sassi R, et al. Trends and predictors of repeat mental health visits to a pediatric emergency Department in Hamilton, Ontario. J Can Acad Child Adolesc Psychiatry. 2019;28(2):82

55. Bardach NS, Coker TR, Zima BT, Murphy JM, Knapp P, Richardson LP, et al. Common and costly hospitalizations for pediatric mental health disorders. Pediatrics. 2014;133(4):602-9. https://doi.org/10.1542/peds. 2013-3165.

56. Zima BT, Rodean J, Hall M, Bardach NS, Coker TR, Berry JG. Psychiatric disorders and trends in resource use in pediatric hospitals. Pediatrics. 2016. https://doi.org/10.1542/peds.2016-0909.

57. Williams RJ, Nowatzki N. Validity of adolescent self-report of substance use. Subs Use Misuse. 2005;40(3):299-311. https://doi.org/10.1081/JA200049327

58. Statistics Canada. Ontario child health study (OCHS) 2014. 2017. http:// www23.statcan.gc.ca/imdb/p2SV.pl?Function=getSurvey\&SDDS $=3824$ Accessed 10 June 2019.

59. Adamson SJ, Kay-Lambkin FJ, Baker AL, Lewin TJ, Thornton L, Kelly BJ, et al. An improved brief measure of cannabis misuse: the cannabis use disorders identification test-revised (CUDIT-R). Drug Alcohol Depend. 2010;110(1-2):137-43. https://doi.org/10.1016/j.drugalcdep.2010.02.017.

60. Simons J, Correia CJ, Carey KB, Borsari BE. Validating a five-factor marijuana motives measure: relations with use, problems, and alcohol motives. J Couns Psychol. 1998;45(3):265. https://doi.org/10.1037/00220167.45.3.265.

61. Spinella TC, Stewart SH, Barrett SP. Context matters: characteristics of solitary versus social cannabis use. Drug Alcohol Rev. 2019;38(3):316-20. https://doi.org/10.1111/dar.12912.

62. Babor TF, Higgins-Biddle J, Saunders J, Monteiro M. The alcohol use disorders identification test: guidelines for use in. World Health Organization. 2001. https://apps.who.int/iris/handle/10665/67205. Accessed 17 Mar 2021. 
63. Cooper ML. Motivations for alcohol use among adolescents: development and validation of a four-factor model. Psychol Assess. 1994;6(2):117. https://doi.org/10.1037/1040-3590.6.2.117.

64. National Institute on Drug Abuse. NIDA quick screen V1.0. https://www drugabuse.gov/sites/default/files/pdf/nmassist.pdf. Accessed $24 \mathrm{Apr}$ 2021.

65. Kessler RC, Andrews G, Colpe LJ, Hiripi E, et al. Short screening scales to monitor population prevalences and trends in non-specific psychological distress. Psychol Med. 2002;32(6):959. https://doi.org/10.1017/S0033 291702006074

66. Duncan L, Georgiades K, Wang L, Comeau J, Ferro MA, Van Lieshout RJ, et al. The 2014 Ontario child health study emotional behavioural scales
(OCHS-EBS) part I: a checklist for dimensional measurement of selected DSM-5 disorders. Can J Psychiatry. 2019;64(6):423-33. https://doi.org/10 $1177 / 0706743718808250$

67. Bourque J, Afzali MH, O'Leary-Barrett M, Conrod P. Cannabis use and psychotic-like experiences trajectories during early adolescence: the coevolution and potential mediators. J Child Psychol Psychiatry. 2017;58(12):1360-9. https://doi.org/10.1111/jcpp.12765.

\section{Publisher's Note}

Springer Nature remains neutral with regard to jurisdictional claims in published maps and institutional affiliations.
Ready to submit your research? Choose BMC and benefit from:

- fast, convenient online submission

- thorough peer review by experienced researchers in your field

- rapid publication on acceptance

- support for research data, including large and complex data types

- gold Open Access which fosters wider collaboration and increased citations

- maximum visibility for your research: over $100 \mathrm{M}$ website views per year

At BMC, research is always in progress.

Learn more biomedcentral.com/submissions 